Fetal Diagnosis and Therapy

\title{
Early Neurodevelopmental Outcome of Infants with High-Risk Fetal Lung Lesions
}

\author{
Enrico Danzer Jennifer Siegle Jo Ann D’Agostino Marsha Gerdes \\ Casey Hoffman Judy Bernbaum Natalie E. Rintoul Alan W. Flake \\ N. Scott Adzick Holly L. Hedrick
}

The Center for Fetal Diagnosis and Treatment, The Children's Hospital of Philadelphia and The University of Pennsylvania School of Medicine, Philadelphia, Pa., USA

\section{Key Words}

Fetal lung lesion $\cdot$ Fetal intervention $\cdot$ Ex utero intrapartum therapy · Neurodevelopment • Bayley Scales of Infant

Development-III - Wechsler Preschool and Primary Scale of Intelligence-III

\begin{abstract}
Objective: To evaluate the neurodevelopmental outcome of infants with high-risk fetal lung lesions defined as (1) requiring fetal intervention and/or ex utero intrapartum therapy (EXIT), or (2) acute respiratory decompensation postnatally necessitating emergent resection within $48 \mathrm{~h}$ of life. Methods: We reviewed the medical records of 13 consecutive patients with high-risk fetal lung lesions who were enrolled in our prospective interdisciplinary follow-up program. Neurodevelopmental status was evaluated using the Bayley Scales of Infant Development-III (children $\leq 3$ years, $n=12$ ), or the Wechsler Preschool and Primary Scale of Intelligence-III (children $\geq 4$ years, $n=1$ ). Results: Eight children (62\%) underwent prenatal intervention (EXIT, $n=6$; fetal resection, $n=1$; intrauterine shunt placement, $n=1)$, and $5(38 \%)$ required emergent resection postnatally. Median age at evaluation was 25 months (range: $5-80$ ). Average scores for cognitive development were found in all children assessed under 3 years of age. The one child who was tested for cognitive abil-
\end{abstract}

ity at 6 years of age scored in the borderline range of intellectual functioning. For language outcome, 15\% scored above average, $54 \%$ scored within the average range, and $31 \%$ had mild deficits. Overall, $77 \%$ scored within the average range for neuromotor outcome, while $23 \%$ scored within the mildly delayed range. None of the children had severe delays. Cognitive, language, and psychomotor scores were similar between both groups. Hypotonicity was found in $23 \%$. Autism was suspected in one child who underwent an EXIT procedure and was postnatally diagnosed with mosaic trisomy 18. Conclusion: The majority of children with highrisk fetal lung lesions have age-appropriate neurodevelopmental scores.

Copyright $\odot 2012$ S. Karger AG, Basel

\section{Introduction}

Prenatal diagnosis provides insight into the in utero evolution of fetal thoracic lesions such as congenital cystic adenomatoid malformation (CCAM), bronchopulmonary sequestration, congenital lobar emphysema, and mediastinal teratoma. Serial sonographic study of fetuses with thoracic lesions has helped define the natural history of these lesions, determine the pathophysiologic features that affect clinical outcome, and formulate manage-

\section{KARGER}

Fax +41613061234

E-Mail karger@karger.ch

www.karger.com
C) 2012 S. Karger AG, Basel

$1015-3837 / 12 / 0314-0210 \$ 38.00 / 0$

Accessible online at:

www.karger.com/fdt
Holly L. Hedrick, MD

The Center for Fetal Diagnosis and Treatment

5th Floor Wood Center, The Children's Hospital of Philadelphia

34th Street and Civic Center Boulevard, Philadelphia, PA 19104 (USA)

Tel. +1 215590 2747, E-Mail hedrick@email.chop.edu 
ment based on prognosis [1-4]. A large mass may cause mediastinal shift, hypoplasia of normal lung tissue, polyhydramnios, and cardiovascular compromise leading to fetal hydrops and death. Hydrops is a harbinger of fetal or neonatal demise, and manifests itself as fetal ascites, pleural and pericardial effusions, and skin and scalp edema. Thoracic lesions can cause respiratory distress in the newborn period, and the smallest masses may be asymptomatic until later in childhood when infection, pneumothorax, or malignant degeneration may occur. Large fetal lung tumors may regress in size on serial prenatal sonography, illustrating that improvement occasionally can occur during fetal life [5-8].

The finding that fetuses with hydrops are at very high risk for fetal or neonatal demise has led to several therapeutic maneuvers. Antenatal steroids and fetal surgical resection of the massively enlarged pulmonary lobe (fetal lobectomy) have been successfully performed for microcystic/solid lesions [1,9-11], while thoracoamniotic shunting has been effectively utilized for macrocystic lung lesions [12-14]. Lesions with associated hydrops diagnosed late in gestation may benefit from resection using an ex utero intrapartum therapy (EXIT) approach [15].

Although the survival and short- and long-term morbidity of these fetuses has been reviewed extensively $[1,3$, $5-8,16-18]$, little information has been presented about the neurofunctional outcomes in children with high-risk fetal lung lesions [19]. It is increasingly recognized that assessment of neurodevelopmental outcome is fundamental in the evaluation of the impact of novel interventions such as fetal surgery.

Therefore, the objective of this paper is to describe the neurodevelopmental outcome of infants with high-risk fetal lung lesions defined as (1) requiring fetal intervention and/or EXIT, or (2) acute respiratory decompensation postnatally necessitating emergent resection. Patients were subsequently enrolled in our interdisciplinary follow-up program and underwent comprehensive evaluations by pediatric, surgical, and neurodevelopmental specialists at specified intervals. The structured multidisciplinary follow-up facilitates early recognition and treatment for long-term postnatal complications, and may help to prevent secondary morbidities.

\section{Material and Methods}

This study was approved by The Children's Hospital of Philadelphia Institutional Review Board, Committee for Protection of Human Subjects (IRB 2004-5-3779). Informed consent was obtained from the parents or legal guardians.

Neurodevelopmental Outcome and

High-Risk Fetal Lung Lesions

\section{Patient Population}

The initial evaluation at our institution includes detailed fetal ultrasonography and fetal ultrafast MRI. Assessment includes the type of fetal lung lesion, CCAM volume ratio (CVR), placental size and location, and the presence or absence of hydrops. Fetal echocardiography and Doppler flow measurements are performed to assess cardiac anatomy and function. After evaluation, all patients undergo nondirective counseling for management options. The options include (1) termination of pregnancy if the gestational age is $<24$ weeks', (2) standard postnatal care with continued frequent ultrasound scan and echocardiographic surveillance, (3) fetal intervention if the fetus and mother meet criteria, and (4) delivery via the EXIT procedure if the fetus and mother meet criteria.

\section{CCAM Volume Ratio}

The CCAM volume is sonographically measured by using the formula for a prolate ellipse (length $\times$ height $\times$ width $\times 0.52$ ) [20]. In high-risk lung lesions (CVR $>1.6$ or macrocystic), we track the lung mass growth 2-3 times weekly. For low-risk lung lesions $($ CVR $<1.6)$, we initially track growth $1-2$ times per week, and then increase or decrease intervals depending upon observed growth [21].

\section{Fetal Intervention and/or the EXIT Procedure}

The perioperative evaluations and care, the intraoperative and the postoperative management for patients that underwent fetal intervention, and/or the EXIT procedure as well as the indication for prenatal betamethasone administration have been described elsewhere in detail $[1,5,9,10,14,15]$.

\section{Postnatal Management}

Postnatal ventilatory management in the neonatal intensive care unit is similar to the infant with pulmonary hypoplasia from severe congenital diaphragmatic hernia or giant omphalocele [22-24]. The indications for venoarterial extracorporeal membrane oxygenation (ECMO) include failure of conventional therapy as defined by inability to maintain preductal saturations $>85 \%$ or postductal $\mathrm{PaO}_{2}>30$, peak inspiratory pressure $>28 \mathrm{~cm}$ $\mathrm{H}_{2} \mathrm{O}$, mean airway pressure $>15$, pressor-resistant hypotension, or inadequate oxygen delivery with persistent metabolic acidosis. Relative contraindications to ECMO include gestational age $<34$ weeks' gestation and weight $<2.0 \mathrm{~kg}$ [22].

\section{Interdisciplinary Follow-Up Program}

In July 2004, we established an interdisciplinary program to provide standardized follow-up care of all survivors seen at our institution with moderate-to-severe pulmonary hypoplasia and/ or pulmonary hypertension (e.g. congenital diaphragmatic hernia, giant omphalocele, and fetal lung lesion). As part of this program, infants underwent comprehensive and coordinated evaluation by pediatric and surgical specialists and psychologists at specified intervals. The structured interdisciplinary follow-up program was designed to reduce fragmentation of patient care and facilitate early recognition and treatment for long-term postnatal complications in these survivors.

With respect to the current study, survivors with fetal lung lesions were enrolled if they underwent fetal intervention and/or EXIT, or (2) acute respiratory decompensation postnatally necessitating emergent resection at our institution between July 2004 and June 2010. 
Table 1. Baseline patient characteristics and hospital course of children with high-risk fetal lung lesion

\begin{tabular}{lccc}
\hline & $\begin{array}{l}\text { Fetal intervention } \\
(\mathrm{n}=8,62 \%)\end{array}$ & $\begin{array}{l}\text { Emergent postnatal resection } \\
(\mathrm{n}=5,38 \%)\end{array}$ & $\mathrm{p}$ \\
\hline GA at evaluation, weeks & $23.1 \pm 2.9(20-29)$ & $23.8 \pm 4.3(20-30)$ & 0.81 \\
Male gender & $8(100)$ & $4(80)$ & 0.19 \\
CVR, CCAM & $1.7 \pm 2.4(1.0-4.1)$ & $1.8 \pm 0.5(1.3-2.6)$ & 0.51 \\
Prenatal steroids & $5(63)$ & $1(20)$ & 0.13 \\
GA at birth, weeks & $36.3 \pm 1.6(33-38)$ & $37.2 \pm 1.3(36-39)$ & 0.26 \\
Birth weight, g & $3,103.1 \pm 439.7(2,500-3,600)$ & $2,836.0 \pm 541.9(2,065-4,300)$ & 0.38 \\
Length of ventilator support, days & $14.6 \pm 14.2(1-43)$ & $9.6 \pm 15.4(1-37)$ & 0.57 \\
Type of ventilation & $7(88) / 1(12)$ & $5(100) / 0(0)$ & $\mathrm{NA}$ \\
IMV/HFOV & $3(38)$ & 0 & $\mathrm{NA}$ \\
ECMO & $3(38)$ & $1(20)$ & 0.51 \\
Pulmonary vasodilator use & $38.1 \pm 27.1(8-88)$ & $33.0 \pm 30.3(11-84)$ & 0.77 \\
Age at discharge, days & $3(38)$ & $1(20)$ & 0.51 \\
O dependent at DOL 30 & & & \\
\hline
\end{tabular}

Data are presented as means $\pm \mathrm{SD}$ (range) or $\mathrm{n}(\%) . \mathrm{GA}=$ Gestational age; CVR = CCAM volume ratio; IMV = intermittent mandatory ventilation; HFOV = high-frequency oscillatory ventilation; NA = not applicable; DOL = day of life.

Neurodevelopmental Assessment

Infants were assessed using either the Bayley Scales of Infant Development-III (BSID-III) or Wechsler Preschool and Primary Scale of Intelligence (WPPSI-III, children older than 4 years). The BISD-III yields scores on 3 domains: cognitive, language, and neuromotor developmental outcome. The WPPSI-III provides verbal IQ and performance IQ scores as well as the full scale IQ. The mean score for all tests was 100, with a SD of 15; the lowest assigned score was 50 . A score of $\leq 70$ is 2 SD below the mean. Scores were grouped as average, mildly delayed, and severely delayed by SD intervals $(115-85,71-84, \leq 70)$. The neuromuscular examination (active tone, passive tone, reflexes, gross motor abilities, and fine motor abilities) was classified as normal if no abnormalities affecting motor skills were noted, suspect if a moderate degree of abnormality was noted, and abnormal if functionally significant abnormalities of tone, reflexes, or motor skills were present. Scores were grouped as average, mildly delayed, and severely delayed by SD intervals $(115-85,71-84, \leq 70)$. The neuromuscular examination (active tone, passive tone, reflexes, gross motor abilities, and fine motor abilities) was classified as normal if no abnormalities affecting motor skills were noted, suspect if a moderate degree of abnormality was noted, and abnormal if functionally significant abnormalities of tone, reflexes, or motor skills were present. The DSM-IV diagnostic criteria for autism were used to evaluate for autism spectrum disorder.

\section{Statistical Analysis}

Differences between groups were determined using a $\chi^{2}$ test or two-sided Student's t test when appropriate. Continuous data are expressed as means $\pm \mathrm{SD}$ (median, range). Categorical data are expressed as proportions. $\mathrm{p}<0.05$ was considered statistically significant. All statistical tests were performed using JMP statistical software package (V 7.0; SAS Corp., Cary, N.C., USA).

\section{Results}

\section{Patient Population}

During the study period, 466 pregnant women underwent onsite evaluation for a prenatally diagnosed lung lesion at our center. Nineteen patients who received prenatal and postnatal care at our institution were subsequently enrolled in our interdisciplinary follow-up program. Of those, 13 (68\%) underwent either fetal intervention and/or EXIT delivery $(\mathrm{n}=8,62 \%)$, or required emergent resection within the first $48 \mathrm{~h}$ postnatally due to acute respiratory decompensation $(n=5,38 \%)$; were at least 5 months of age; and had returned for detailed neurodevelopmental assessment. Baseline patient characteristics and hospital course of the study population are summarized in table 1 . Of the 8 children who required fetal intervention and/or EXIT delivery, 4 (50\%) presented with varying degrees of fetal hydrops. The overall short-term complications for each of the 13 children are listed in table 2.

One child who underwent an EXIT procedure was found postnatally to have mosaic trisomy 18 . Seven (55\%) had CCAM lesions, 2 (15\%) had hybrid lesions, 2 (15\%) CCAM and congenital lobar emphysema, and 2 (15\%) bronchopulmonary sequestration only. Of the 6 children who either did not return for follow-up evaluation or are currently too young for detailed neurological assessment, 
Table 2. Short-term complications of the study population

\begin{tabular}{rlll}
\hline Case & Fetal intervention & $\begin{array}{l}\text { GA at birth } \\
\text { weeks }\end{array}$ & Short-term complications \\
\hline 1 & EXIT & 36 & bilateral chylothorax, RSV, UTI \\
2 & Shunt/EXIT & 37 & GERD $^{1}$ \\
3 & Betamethasone/fetal resection & 37 & none \\
4 & Betamethasone/EXIT & 38 & asthma, GERD ${ }^{2}$ \\
5 & Betamethasone/EXIT & 37 & laryngomalacia \\
6 & Betamethasone/EXIT & 35 & GERD \\
7 & Betamethasone/shunt/EXIT & 33 & failure to thrive \\
8 & Shunt & 37 & none \\
9 & NA & 38 & persistent air leak \\
10 & NA & 37 & VSD repair \\
11 & NA & 36 & cleft lip/palate \\
12 & NA & 36 & hydrocele \\
13 & NA & 39 & none \\
\hline
\end{tabular}

RSV = Respiratory syncytial virus; UTI = urinary tract infection; GERD = gastroesophageal reflux disease; VSD = ventricular septal defect.

${ }^{1}$ Managed medically.

${ }^{2}$ Requiring fundoplication.

4 required prenatal intervention (e.g. shunt placement, $\mathrm{n}=3$; EXIT delivery, $\mathrm{n}=1$ ) and 2 underwent emergent resection postnatally. Overall patient characteristics were similar when compared to the study population (data not shown).

\section{Neurodevelopmental Outcome}

Each child's most recent neurodevelopmental and neurological assessment (i.e. muscle tone and strength) were used for analysis. At the time of neurodevelopmental testing, the mean age of the study group was $27.2 \pm$ 18.3 months (median: 25; range: 5-80). One child was younger than 12 months at evaluation, 4 (31\%) were between 12 and 24 months, 7 (53\%) between 25 and 36 months, and 1 (8\%) was 6 years of age ( 80 months).

Compared to standard normograms, the mean weight percentile, mean height percentile, and mean head circumference percentile were $29.9 \pm 29.3$ (range: $3-90$ ), 36 \pm 27.5 (range: $4-90$ ), and $57.2 \pm 19.1$ (range: $30-85$ ), respectively. None of the children had microcephaly, sensorineural hearing loss, or vision impairment. Cranial imaging studies (head ultrasound and/or brain MRI) performed during the neonatal period were available in 10 (77\%). Of those, one child had grade 1 intraventricular hemorrhage, 3 (30\%) had enlargement of the extra-axial fluid spaces, 2 (20\%) had evidence of periventricular leukomalacia, and 2 presented with small periventricular cysts (20\%). None of the children had seizures or intraparenchymal hemorrhage. There were no cases of cerebral palsy among the 13 children. Autism is suspected in the child with mosaic trisomy 18 . Neuromuscular hypotonicity was found in 3 patients (23\%).

Neurodevelopmental status was evaluated using the BSID-III (children $\leq 3$ years, $\mathrm{n}=12$ ), or the WPPSI-III (children $\geq 4$ years, $\mathrm{n}=1$ ). The mean BSID-III cognitive, language, and neuromotor scores for the entire cohort were $96.3 \pm 7.1$ (range: $85-105$ ), $96.4 \pm 16.1$ (range: $71-$ 124), and $98.9 \pm 13.2$ (range: $73-121$ ), respectively. The WPPSI-III verbal IQ, WPPSI-III performance IQ, and WPPSI-III full scale IQ scores for the one patient who underwent neurocognitive evaluation at 80 months of age were 74,77 , and 73 , respectively.

Based on the individual testing scores, average scores for cognitive development were measured in all children assessed under 3 years of age. The one child who was tested for cognitive ability at 6 years of age scored in the borderline range of intellectual functioning. For developmental language outcomes, $15 \%$ of children scored above average, 54\% scored within the average range, and 31\% had mild deficits. Overall, 77\% scored within the average range for neuromotor outcome, while $23 \%$ scored within the mildly delayed range. Of note, none of the children with high-risk fetal lung lesion had severe neurodevelopmental or neurofunctional deficits at follow-up. As sum- 
Table 3. Comparison of BSID-III scores in 12 children with high-risk fetal lung lesion

\begin{tabular}{lcll}
\hline & Fetal intervention & Emergent postnatal resection & $\mathrm{p}$ \\
\hline Cognitive scores & $97.3 \pm 6.9(85-105)$ & $95.0 \pm 7.9(85-105)$ & 0.31 \\
Language scores & $96.7 \pm 16.4(79-124)$ & $96.0 \pm 17.6(71-118)$ & 0.47 \\
Motor scores & $101.0 \pm 16.2(73-121)$ & $96.4 \pm 9.6(82-103)$ & 0.29 \\
\hline \multicolumn{2}{c}{ Data presented as mean \pm SD (range). } & \\
\hline
\end{tabular}

marized in table 3, neurological outcomes were found to be similar between groups.

Of the 3 children who required ECMO therapy, average neurocognitive, language, and neuromotor scores were found in 2, 1, and 3 patients, respectively. One ECMO child had borderline neurocognitive function and 2 had mild language deficits.

\section{Discussion}

The main objective of this study was to evaluate the neurodevelopmental and neurofunctional performance of 13 children with high-risk fetal lung lesions who underwent standardized prenatal care and postnatal management at a single high-volume institution. Our results demonstrate that the neurological outcome at a median of 25 months was within normal limits for the majority of children with high-risk fetal lung lesions. Additionally, mean scores of the entire group for cognitive, language, and psychomotor outcome were similar to population norms. Importantly, neither fetal intervention nor the need for emergent postnatal resection was associated with significant neurodevelopmental delays or neurological dysfunction.

The provided information on the neurodevelopmental outcome of children with prenatally diagnosed high-risk fetal lung lesion may be of major interest for obstetricians, pediatric surgeons, and neonatologists involved in pregnancy counseling and the pre- and postnatal care of these children. Our results confirm and expand on the limited available data on the neurodevelopmental outcome after fetal intervention for high-risk lung lesions [19]. Gibbs et al. [19] reported previously on four children with hydropic CCAM lesions who underwent open fetal resection between 22 and 25 weeks' gestation and were subsequently delivered prematurely between 25 and 34 weeks' gestation. Similar to our findings, neurodevelopmental testing was normal in 3 cases at follow-up, one had mild neuro- motor delays, and none of the children had significant neurocognitive or neurological delays.

Despite these promising results, several aspects regarding the various fetal intervention techniques that were used in the current study warrant commenting. Most lung lesions require no fetal intervention and can be managed postnatally as described previously with excellent outcomes $[1,5,6,8,25]$. CCAMs that present with CVRs of 1.6 or higher are a high-risk category and require close surveillance. We [26] and others [27, 28] have observed growth arrest of these tumors with prenatal steroid therapy. At the present time, we empirically treat microcystic/solid CCAMs at risk for evolution of hydrops, or in early stages of hydrops, with steroids before considering fetal intervention. If signs of hydrops persist or progress in a fetus of $<32$ weeks' gestation, fetal surgery is indicated: either open resection for microcystic lesions or thoracoamniotic shunt placement for macrocystic lesions with a single dominant cyst $[1,5,13,14,18]$. If hydrops develops in a fetus after 32 weeks' gestation, or if there is persistence of major mediastinal shift closer to term, we recommend delivery and resection by the EXIT procedure [15].

The present study has several limitations. Although our study is currently the largest report on neurological outcome in children with high-risk fetal lung lesions, the modest sample size of 13 study participants limited our ability to perform meaningful statistical analysis of potential patient-specific predictors for those children with adverse neurodevelopmental outcome. It is possible that a larger sample size would have yielded different results. For additional critical evaluation of our findings and definition of potential risk factors of adverse neurodevelopmental outcome, a larger multi-institutional study will be necessary. Also, despite the fact that the majority of enrolled lung lesion patients (68\%) underwent neurodevelopmental evaluation, data may not accurately reflect the outcome of the entire group, resulting in both type I and II errors in interpretation. Furthermore, the predictive value of neurodevelopmental testing before 3 years of age 
is limited. The full extent of neurological problems is often not recognized until much later in life when more complex cognitive and executive functioning skills are required. The BSID-III was used for all children younger than 4 years as it provides a good assessment of current developmental strength and weaknesses. The BSID-III is, however, not an intelligence test, and assessment of infant mental and motor performance correlates only modestly with performance later in life. Longitudinal follow-up studies are planned and will be important to identify potential neurodevelopmental deficits in other domains.

In conclusion, the majority of children with high-risk fetal lung lesions have age-appropriate neurodevelopmental scores. Our data, however, warrant corroboration in larger studies for risk factor stratification and validation by long-term assessment.

\section{References}

1 Adzick NS: Management of fetal lung lesions. Clin Perinatol 2009;36:363-376.

$\checkmark 2$ Dommergues M, Louis-Sylvestre C, Mandelbrot L, Aubry MC, Revillon Y, Jarreau PH, Dumez Y: Congenital adenomatoid malformation of the lung: when is active fetal therapy indicated? Am J Obstet Gynecol 1997; 177:953-958.

-3 Miller JA, Corteville JE, Langer JC: Congenital cystic adenomatoid malformation in the fetus: natural history and predictors of outcome. J Pediatr Surg 1996;31:805-808.

4 Sakala EP, Perrott WS, Grube GL: Sonographic characteristics of antenatally diagnosed extralobar pulmonary sequestration and congenital cystic adenomatoid malformation. Obstet Gynecol Surv 1994;49:647655.

5 Adzick NS, Harrison MR, Crombleholme TM, Flake AW, Howell LJ: Fetal lung lesions: management and outcome. Am J Obstet Gynecol 1998; 179:884-889.

-6 MacGillivray TE, Harrison MR, Goldstein RB, Adzick NS: Disappearing fetal lung lesions. J Pediatr Surg 1993;28:1321-1324.

7 Saltzman DH, Adzick NS, Benacerraf BR: Fetal cystic adenomatoid malformation of the lung: apparent improvement in utero. Obstet Gynecol 1988;71:1000-1002.

8 Laberge JM, Flageole H, Pugash D, Khalife S, Blair G, Filiatrault D, Russo P, Lees G, Wilson RD: Outcome of the prenatally diagnosed congenital cystic adenomatoid lung malformation: a Canadian experience. Fetal Diagn Ther 2001;16:178-186.

$\checkmark 9$ Adzick NS, Harrison MR, Flake AW, Howell LJ, Golbus MS, Filly RA: Fetal surgery for cystic adenomatoid malformation of the lung. J Pediatr Surg 1993;28:806-812.

$\checkmark 10$ Harrison MR, Adzick NS, Jennings RW, Duncan BW, Rosen MA, Filly RA, Goldberg JD, deLorimier AA, Golbus MS: Antenatal intervention for congenital cystic adenomatoid malformation. Lancet 1990;336:965-967.

11 Peranteau WH, Merchant AM, Hedrick HL, Liechty KW, Howell LJ, Flake AW, Wilson RD, Johnson MP, Bebbington MW, Adzick NS: Prenatal course and postnatal management of peripheral bronchial atresia: association with congenital cystic adenomatoid malformation of the lung. Fetal Diagn Ther 2008;24:190-196.

12 Bernaschek G, Deutinger J, Hansmann M, Bald R, Holzgreve W, Bollmann R: Feto-amniotic shunting-report of the experience of four European centres. Prenat Diagn 1994; 14:821-833.

13 Mann S, Johnson MP, Wilson RD: Fetal thoracic and bladder shunts. Semin Fetal Neonatal Med 2010;15:28-33.

14 Wilson RD, Baxter JK, Johnson MP, King M, Kasperski S, Crombleholme TM, Flake AW, Hedrick HL, Howell LJ, Adzick NS: Thoracoamniotic shunts: fetal treatment of pleural effusions and congenital cystic adenomatoid malformations. Fetal Diagn Ther 2004;19: 413-420.

$>15$ Hedrick HL, Flake AW, Crombleholme TM, Howell LJ, Johnson MP, Wilson RD, Adzick NS: The ex utero intrapartum therapy procedure for high-risk fetal lung lesions. J Pediatr Surg 2005;40:1038-1043.

16 Adzick NS, Harrison MR: Management of the fetus with a cystic adenomatoid malformation. World J Surg 1993;17:342-349.

17 Adzick NS, Harrison MR, Glick PL, Golbus MS, Anderson RL, Mahony BS, Callen PW, Hirsch JH, Luthy DA, Filly RA: Fetal cystic adenomatoid malformation: prenatal diagnosis and natural history. J Pediatr Surg 1985;20:483-488.

18 Cass DL, Olutoye OO, Cassady CI, Moise KJ, Johnson A, Papanna R, Lazar DA, Ayres NA, Belleza-Bascon B: Prenatal diagnosis and outcome of fetal lung masses. J Pediatr Surg 2011;46:292-298.

19 Gibbs DL, Piecuch RE, Graf JL, Leonard CH, Farrell JA, Harrison MR: Neurodevelopmental outcome after open fetal surgery. J Pediatr Surg 1998;33:1254-1256.

20 Crombleholme TM, Coleman B, Hedrick H, Liechty K, Howell L, Flake AW, Johnson M, Adzick NS: Cystic adenomatoid malformation volume ratio predicts outcome in prenatally diagnosed cystic adenomatoid malformation of the lung. J Pediatr Surg 2002;37: 331-338.

21 Mahle WT, Rychik J, Tian ZY, Cohen MS, Howell LJ, Crombleholme TM, Flake AW, Adzick NS: Echocardiographic evaluation of the fetus with congenital cystic adenomatoid malformation. Ultrasound Obstet Gynecol 2000;16:620-624.

22 Hedrick HL, Danzer E, Merchant A, Bebbington MW, Zhao H, Flake AW, Johnson MP, Liechty KW, Howell LJ, Wilson RD, Adzick NS: Liver position and lung-to-head ratio for prediction of extracorporeal membrane oxygenation and survival in isolated left congenital diaphragmatic hernia. Am J Obstet Gynecol 2007;197:422.e1-e4.

23 Danzer E, Gerdes M, Bernbaum J, D’Agostino J, Bebbington MW, Siegle J, Hoffman C, Rintoul NE, Flake AW, Adzick NS, Hedrick HL: Neurodevelopmental outcome of infants with congenital diaphragmatic hernia prospectively enrolled in an interdisciplinary follow-up program. J Pediatr Surg 2010; 45:1759-1766.

24 Danzer E, Gerdes M, D’Agostino JA, Bernbaum J, Siegle J, Hoffman C, Rintoul NE, Liechty KW, Flake AW, Adzick NS, Hedrick HL: Prospective, interdisciplinary follow-up of children with prenatally diagnosed giant omphalocele: short-term neurodevelopmental outcome. J Pediatr Surg 2010;45:718-723.

25 Tsai AY, Liechty KW, Hedrick HL, Bebbington M, Wilson RD, Johnson MP, Howell LJ, Flake AW, Adzick NS: Outcomes after postnatal resection of prenatally diagnosed asymptomatic cystic lung lesions. J Pediatr Surg 2008;43:513-517.

26 Peranteau WH, Wilson RD, Liechty KW, Johnson MP, Bebbington MW, Hedrick HL, Flake AW, Adzick NS: Effect of maternal betamethasone administration on prenatal congenital cystic adenomatoid malformation growth and fetal survival. Fetal Diagn Ther 2007;22:365-371.

27 Curran PF, Jelin EB, Rand L, Hirose S, Feldstein VA, Goldstein RB, Lee H: Prenatal steroids for microcystic congenital cystic adenomatoid malformations. J Pediatr Surg 2010;45:145-150.

28 Tsao K, Hawgood S, Vu L, Hirose S, Sydorak R, Albanese CT, Farmer DL, Harrison MR, Lee H: Resolution of hydrops fetalis in congenital cystic adenomatoid malformation after prenatal steroid therapy. J Pediatr Surg 2003;38:508-510. 